\title{
CRAPANZANO (Vincent), LesHamadcha. Une étude d'ethnopsychiatrie marocaine
}

Paris, Institut d'Édition Sanofi-Synthélabo, 2000, 386 p. (trad. de l'anglais par Olivier Ralet) (bibliogr., glossaire)

\section{Constant Hamès}

\section{(2) OpenEdition}

Journals

Édition électronique

URL : http://journals.openedition.org/assr/20397

DOI : $10.4000 /$ assr.20397

ISSN : $1777-5825$

Éditeur

Éditions de l'EHESS

Édition imprimée

Date de publication : 31 décembre 2000

Pagination : 147

ISBN : 2-222-96698-1

ISSN : 0335-5985

Référence électronique

Constant Hamès, "CRAPANZANO (Vincent), LesHamadcha. Une étude d'ethnopsychiatrie marocaine », Archives de sciences sociales des religions [En ligne], 112 I octobre-décembre 2000, document 112.68, mis en ligne le 19 août 2009, consulté le 21 septembre 2020. URL : http://journals.openedition.org/ assr/20397; DOI : https://doi.org/10.4000/assr.20397

Ce document a été généré automatiquement le 21 septembre 2020

(c) Archives de sciences sociales des religions 


\section{CRAPANZANO (Vincent), LesHamadcha. Une étude d'ethnopsychiatrie marocaine}

Paris, Institut d'Édition Sanofi-Synthélabo, 2000, 386 p. (trad. de l'anglais par Olivier Ralet) (bibliogr., glossaire)

\section{Constant Hamès}

\section{RÉFÉRENCE}

CRAPANZANO (Vincent), LesHamadcha. Une étude d'ethnopsychiatrie marocaine,Paris, Institut d'Édition Sanofi-Synthélabo, 2000, 386 p. (trad. de l'anglais par Olivier Ralet)

(bibliogr., glossaire)

1 La traduction française de ce travail américain sur un terrain « ethnographique » au Maroc, dans les années 1967-1968, n'est probablement pas due à la consécration d'un classique du genre mais bien plus, à notre avis, au renouveau de l'actualité religieuse musulmane et, particulièrement au Maroc, au succès récent de certaines formes de rituels de confréries islamiques qui se «mondialisent ». V.C. a eu le mérite, quelques années après Gellner, c'est-à-dire à une époque de laïcisation et de silence religieux, de mener une enquête sur une confrérie islamique, les Hamadcha, qui pouvait passer, comme toutes les autres manifestations du religieux islamique, pour marginale, voire menacée d'extinction: un véritable «objet » ethnographique! Aujourd'hui, l'auteur explique dans une très courte préface, que les temps ont changé et ont œuvré en faveur du succès des démonstrations rituelles corporelles et musicales des Hamadcha : " Je me suis souvenu de la manière dont les officiels du gouvernement m'avaient dit, en 1967, que je perdais mon temps à étudier un ordre religieux qui était en train de disparaître. Aujourd'hui le gouvernement - sans doute ces mêmes officiels qui m'avaient découragé - les honoraient...» (p. 14). 
2 L'aspect le plus actuel probablement de la confrérie des Hamadcha réside dans leur fonction de recours thérapeutique, qui semble bien être, sur la planète mondialisée, la chose la plus recherchée dans les religions et les magies anciennes et nouvelles. Or c'est justement cette caractéristique thérapeutique attachée au groupe Hamadcha de Meknès et des environs que V.C. a mise en vedette dans son travail. Il reconnaît luimême (toujours p.14) que la tendance à en faire une lecture psychanalytique correspondait bien plus à un « reflet de l'époque » qu'à une interprétation scientifique « universelle ». Incontestablement, à trente années de distance, on gardera de ce travail, à l'instar de celui de Brunel de 1925 sur les Ais-saoua, la remarquable qualité de l'observation et de la description de terrain, à propos de l'organisation sociale, des légendes et surtout des rituels confrériques eux-mêmes, censés guérir. La question des jinn, par exemple, " tarte à la crème » de l'anthropologie musulmane actuelle, y est remarquablement analysée.

3 Le traducteur, qui a parsemé la traduction de notes tout à fait bienvenues, a adapté une translittération de l'arabe (déjà translittéré par un Américain!) que l'on qualifiera de variée, avec de petites inexactitudes (la lettre jim ne se prononce pas j en Égypte mais $\mathrm{g}$; on ne peut pas écrire l-cAyn Kabîr mais l-cAyn al-Kabîr ; absence totale des voyelles longues etc.). Mais il faut bien avouer que dans ce domaine, à force de vouloir simplifier ou d'adapter pour un mythique "grand public », tout le monde finit par y perdre son latin! Glossaire, bibliographie. 